\title{
NEW MATERIALS FOR RECTUS MUSCLE TENDON EXTENSION IŃ STRABISMUS SURGERY
}

\author{
R. K. AGGARWAL ${ }^{1}$, H. E. WILLSHAW ${ }^{2}$ and P. TOWNSEND ${ }^{3}$ \\ Birmingham
}

\begin{abstract}
SUMMARY
Conventional strabismus surgery has both limitations and complications. Some of these have been overcome by the use of 'hang-back' sutures. Here we describe a new technique using Mersilene and Teflon as extraocular muscle implants for large muscle recessions. Results of initial studies in rabbits are presented and discussed. Mersilene implants evoked a marked fibroblastic reaction which limits their usefulness. Results with Teflon were more encouraging and suggest that it would be a useful spacer material in tendon extensions.
\end{abstract}

Strabismus affects $2-3 \%$ of the population in the United Kingdom. Its surgical correction may be for cosmetic and/or functional reasons, and it is the second most commonly performed ophthalmic operation after cataract surgery, accounting for over 250000 operations per year in England alone.

To weaken a muscle it is conventional to recess it by moving its insertion closer to its point of origin. The maximum effect is achieved when the new position coincides with the tangential point of the globe when the eye moves into the field of action of that muscle. Recessions beyond this point may result in mechanical restriction of ocular movement. ${ }^{1}$ The maximum physiological recession varies for each ocular muscle and approximates to about $8 \mathrm{~mm}$ for the lateral and $6 \mathrm{~mm}$ for the medial rectus muscles. Theoretically, provided the insertion of a muscle remains at or anterior to the point tangential to the globe's surface, the muscle can be slackened without producing limitation of ocular movement. ${ }^{2}$ This is the principle of 'supramaximal' recessions. Here the muscle is recessed using 'loop' or 'hang-back' suture techniques. ${ }^{2,3}$ Attempts to carry out such 'supramaximal' recessions have met with limited success, possibly due to unpredictable and variable reattachments to the globe. , $^{3,4}$

A procedure which would permit predictable 'supramaximal' recessions would be of value, not only when deal-

From: 'Birmingham and Midland Eye Hospital, ${ }^{2}$ Birmingham Children's Hospital, and ${ }^{3}$ University of Birmingham, Birmingham, UK.

Correspondence to: R. K. Aggarwal, Birmingham and Midland Eye Hospital, Church Street, Birmingham B3 2NS, UK. ing with large angle deviations (particularly where surgery would preferably be restricted to one eye) but also in other clinical situations where conventional surgery has proved problematic (such as dissociated vertical deviation, infantile esotropia, congenital nystagmus, Duane's syndrome, Ciancia's syndrome and lateral rectus paralysis).

This article describes a technique using implants to perform large muscle recessions and reports for the first time the results of two materials used as implants.

\section{MATERIALS AND METHODS}

Two implant materials, Mersilene (ethylene glycol and terephthalic acid polymer) and Teflon (PTFE, polytetrafluoroethylene), both of which have been used for other reasons in humans, were tested..$^{5-8}$ The physical properties of the two materials are summarised in Table I. ${ }^{9,10}$

Tendon extension operations were performed on $9 \mathrm{New}$ Zealand White rabbits, using the superior rectus muscle of one eye in each rabbit. All operations were performed under general anaesthesia. The superior conjunctiva of one eye was opened with a limbal incision, the superior rectus muscle was isolated on a muscle hook and then 'extended' using the synthetic material. In 3 eyes Mersilene was used as a sheet extending from the under-surface of the superior rectus to the original insertion of the muscle (Fig. 1). In 3 eyes Teflon was used in sheet form, again sutured to the under-surface of the superior rectus (Fig. 2), and in 3 eyes a Teflon tube was used to surround the superior rectus muscles as a sleeve. As with Mersilene the anterior end of the Teflon was also sutured to the original superior rectus insertion. In all cases Teflon sutures were used to fix the implant and virgin silk sutures to close the conjunctiva. The animals and operation site were

Table I. Physical properties of Mersilene and Teflon

\begin{tabular}{llll}
\hline Material & Chemical nature & Thickness & Character \\
\hline Mersilene & $\begin{array}{l}\text { Ethylene glycol/ } \\
\text { terephthalic acid } \\
\text { polymer mesh } \\
\text { Polytetrafluoroethylene }\end{array}$ & $0.254 \mathrm{~mm}$ & $\begin{array}{l}\text { Mesh, easily torn, } \\
\text { difficult to handle }\end{array}$ \\
\hline
\end{tabular}




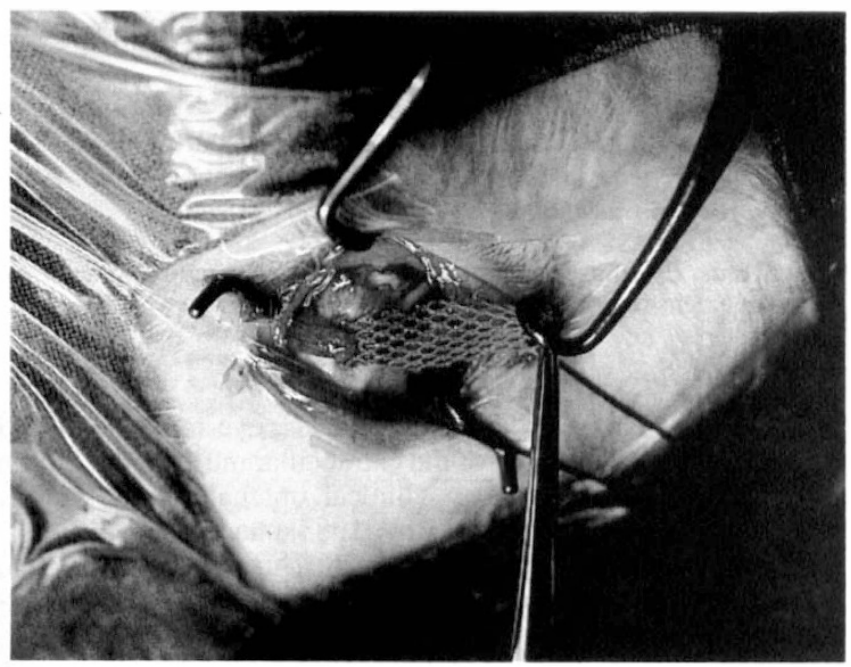

Fig. 1. Operative photograph showing the Mersilene mesh implant sutured to the anterior end of the superior rectus muscle.

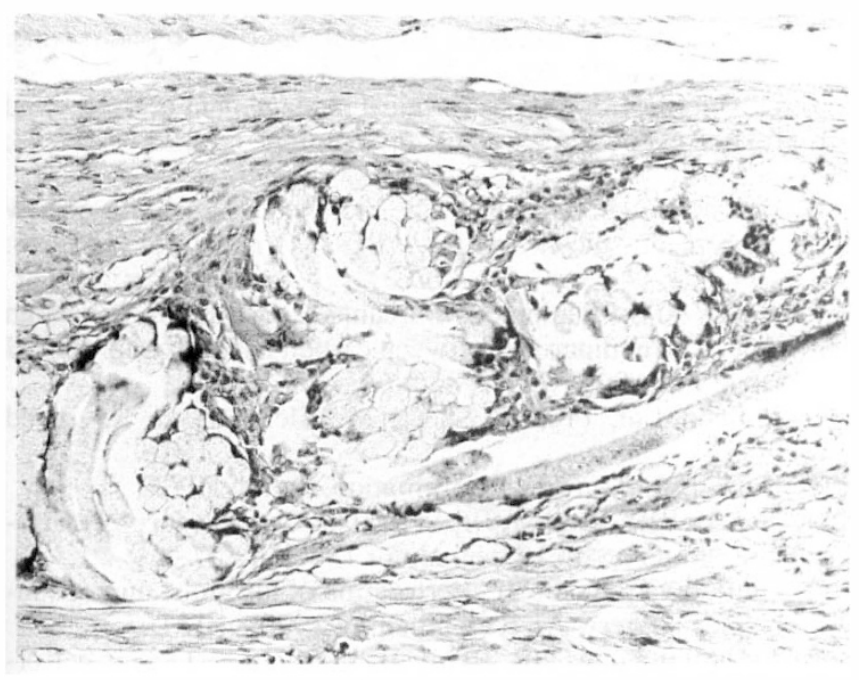

Fig. 2. Microscopic photograph showing the marked mononuclear reaction around the Mersilene mesh both above and below the implant.

checked periodically for gross reactions and complications. The animals were then killed at 4,8 and 12 weeks following surgery and the eyes examined macroscopically and histologically to compare the reactions to the different materials at similar time periods, to assess the degree and type of inflammatory cell reaction around the implant, and to assess the degree and site of adhesions.

\section{RESULTS}

The Mersilene mesh sheet was well tolerated. The eyes looked quiet post-operatively and there was no external sign of irritation around the eye, or of distress in the animals. None of these implants showed any signs of infection or extrusion. However, all 3 of the Mersilene implants showed a marked mononuclear cell reaction around the implant with both macroscopic and microscopic adhesions between implant and sclera and between implant and conjunctiva along the full length of the implant (Fig. 2).

The Teflon was obviously visible, bulging under the

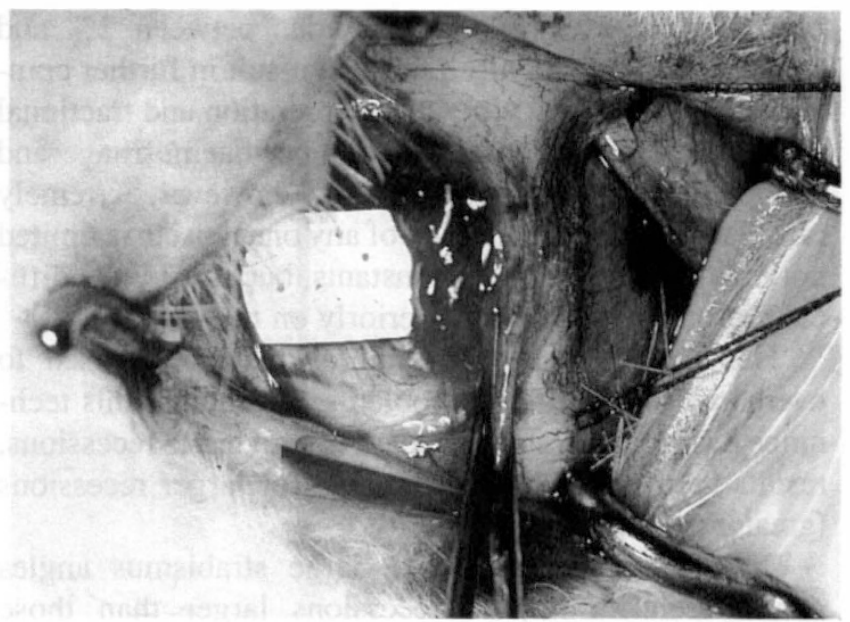

Fig. 3. Operative photograph showing the Teflon implant sutured to both the anterior end of the superior rectus mascle and the muscle's previous insertion.

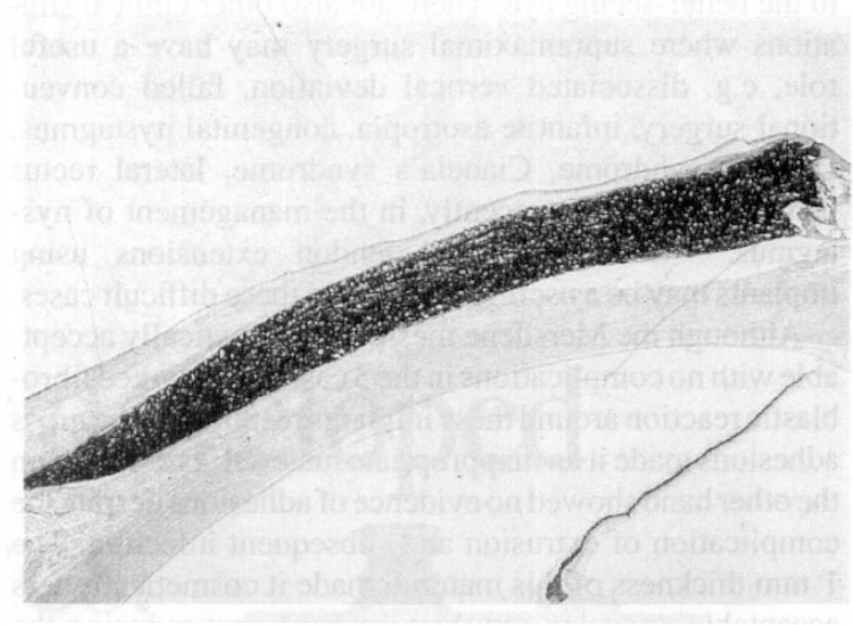

Fig. 4. Microscopic photograph showing a minimal inflammatory reaction around the Teflon implant.

conjunctiva (more obviously in tube form) and hence would be cosmetically less acceptable. All 6 implants showed minimal extrusion from the limbal end where the conjunctiva had been opened at the time of surgery, and all 6 showed macroscopic and microscopic evidence of infection. Cultures of swabs identified a mixed growth of Pasteurella and Aceinetobacter species (both of which are usually commensals in the rabbit). Despite the presence of infection none of these implants showed any macroscopic adhesions to the sclera or conjunctiva; a squint hook could be passed freely above and below the implants without resistance. The microscopic features were consistent with infection rather than a fibrous reaction (Fig. 4).

\section{DISCUSSION}

Conventional strabismus surgery, though relatively safe, has both problems and limitations. It is one of the commonest procedures performed by ophthalmologists. Accidental ocular perforation during intrascleral passage of the 
needle is relatively high and varies between $2 \%$ and $12 \%{ }^{11-14}$ If not recognised this can result in further complications (including vitreous incarceration and tractional retinal detachment, posterior chamber haemorrhage and endophthalmitis) ${ }^{15-18}$ all of which are, however, extremely rare. The amount of recession of any one muscle is limited not only by physiological constants, but also bý the difficulty of placing sutures posteriorly on the globe.

'Hang-back' suspension sutures have been used to overcome some of these problems, but though this technique has met with some success for moderate recessions, results seem to be less predictable for larger recessions (greater than $6 \mathrm{~mm}$ ). ${ }^{4}$

There are occasions when large strabismus angles would seem to require recessions larger than those currently practised. In order to deal with large angles of deviation, surgery on both eyes may be performed. Despite the relatively low incidence of complications with conventional surgery, this poses a particular problem when visual considerations demand that surgery be concentrated on one eye alone, rather than risk surgical injury to the better-seeing eye. There are also other clinical situations where supramaximal surgery may have a useful role, e.g. dissociated vertical deviation, failed conventional surgery, infantile esotropia, congenital nystagmus, Duane's syndrome, Ciancia's syndrome, lateral rectus paralysis and, more recently, in the management of nystagmus. ${ }^{19}$ We believe that tendon extensions using implants may be a useful technique in these difficult cases.

Although the Mersilene mesh was cosmetically acceptable with no complications in the 3 cases, the marked fibroblastic reaction around these implants resulting in the gross adhesions made it an inappropriate material. The Teflon on the other hand showed no evidence of adhesions despite the complication of extrusion and subsequent infection. The $1 \mathrm{~mm}$ thickness of this material made it cosmetically less acceptable, especially in the tube form, but reducing the thickness and using it as a spacer should overcome these difficulties. If an implant of reduced thickness is used and the problems of extrusion and resulting infection are overcome Teflon could be a useful implant material.

To pursue this further we are at present conducting experiments using $0.1 \mathrm{~mm}$ Teflon in sheet and tube form. We are also using a limbal-based conjunctival flap which is tightly sutured with virgin silk at the end of the operation. Initial results suggest that this will prevent the problem of extrusion and resulting infection.

\section{CONCLUSION}

A procedure which would permit predictable 'supramaximal' recessions would be of value for difficult cases of strabismus. Previous attempts at tendon extension in extraocular muscle surgery have been made using fascia lata $^{20,21}$ and plastic implants. ${ }^{22,23}$ In the last 20 years many new materials with improved qualities and different properties have become available. Teflon is one such material, and our initial studies suggest that it would be a useful spacer material, providing another dimension to strabismus surgery where conventional techniques seem inadequate.

We wish to thank Professor D. Morton, Department of Biomedical Sciences, and Dr. J. Harry, Department of Ocular Pathology, for their assistance in this work.

Key words: Eye muscle surgery, Implants, Pseudotendon, Strabismus, Tendon extension.

\section{REFERENCES}

1. Marshall Parks. Extraocular muscles, eye movements and positions, innervation of the extraocular muscles. In: Duane TD, Jaegar EA, editors. Clinical ophthalmology, vol. 1. Philadelphia: Harper and Row 1985: chap 1-3.

2. Reinecke RD. Muscle surgery. In: Duane TD, Jaegar EA, editors. Clinical ophthalmology, Vol. 5. Philadelphia: Harper and Row 1985: chap 9.

3. Jampolsky A. Current techniques of adjustable strabismus surgery. Am J Ophthalmol 1979;88:406-8.

4. Repka MX, Fishman PJ, Guyton DL. The site of reattachment of the extraocular muscle following hang-back recessions. J Pediatr Ophthalmol Strabismus 1990;27:286-90.

5. Downes RN, Collin JRO. The Mersilene mesh ptosis sling. Eye 1990;4:456-63.

6. Downes RN, Jordan K. Surgical management of dysthyroid related eyelid retraction using Mersilene mesh. Eye 1989;3: 385-90.

7. Downes RN, Collin JRO. The Mersilene mesh sling - a new concept in ptosis surgery. $\mathrm{Br} \mathrm{J}$ Ophthalmol 1989;73: 498-501.

8. Amiss AA. Filamentous implant reconstruction of tendon defects: a comparison between carbon and polyester fibre. J Bone Joint Surg (Br) 1982;5:643-82.

9. Ethicon Ltd. Product Sheet: Mersilene mesh. Reviewed 9/85.

10. Du Pont Ltd. Product Information. Teflon PTFE.

11. Hanver WH, Kimball OP. Scleral perforation during strabismus surgery. Am J Ophthalmol 1960;50:807-8.

12. Gottleib FG, Castro JL. Perforation of the globe during strabismus surgery. Arch Ophthalmol 1970;84:151-7.

13. Apple DJ, Jones GR, Reidy JJ, Loftfield K. Ocular perforation and phthisis bulbi secondary to strabismus surgery. $\mathrm{J}$ Pediatr Ophthalmol Strabismus 1985;22:184-7.

14. Morris RJ, Rosen PH, Fells P. Incidence of inadvertent globe perforation during strabismus surgery. Br J Ophthalmol 1990;74:490-3.

15. Wagner RS, Nelson LR. Complications following strabismus surgery. Int Ophthalmol Clin 1985;25(4):171-8.

16. Basmadjian G, Labelle P, Dumas J. Retinal detachment after strabismus surgery. Am J Ophthalmol 1975;79:305-9.

17. Greenberg DR, Ellenhorn NL, Chapman LI, Miller MT, Folk ER. Posterior chamber haemorrhage during strabismus surgery. Am J Ophthalmol 1988;106:634-5.

18. Salamon SM, Friberg TR, Luxenberg MN. Endophthalmitis after strabismus surgery. Am J Ophthalmol 1982;93:39-41.

19. Lee JP. Surgical management of nystagmus. Eye 1988;2: 44-7.

20. Focosi M, Salvi G, Frosini R. Tendon-lengthening by fascia lata graft to weaken action of extraocular muscles. Proceedings of the tenth meeting of the CESSD, Athens, 1979: 96-102.

21. Boschi MC, Frosini R. The problem of the arc of contact: our experience with Focosi's tendon lengthening. Proceedings of the European Strabismus Association. 1982:481-98.

22. Morates AG, Polack FM, Arata AF. Silicone implant to extraocular muscles. Br J Ophthalmol 1966;50:235-44.

23. Dunlap EA. Plastic implants in muscle surgery. Arch Ophthalmol 1968;80:249-57. 